\title{
Pollution-induced behavioural effects in the brown bullhead (Ameiurus nebulosus)
}

\author{
Ross D. Breckels $\cdot$ Bryan D. Neff
}

Accepted: 5 July 2010/Published online: 17 July 2010

(C) Springer Science+Business Media, LLC 2010

\begin{abstract}
Aquatic ecosystems are major sinks for pollutants which can have adverse effects on biodiversity. Thus, it is important to understand the nature of pollutioninduced change in aquatic ecosystems. We show that brown bullheads (Ameiurus nebulosus) may have evolved in response to chronic pollution exposure. We collected adults from the Detroit River (polluted site) and Belle River (control site). Both adults and common-garden raised juveniles were tested for aggression, locomotion, and escape response using consecutive unchallenged (clean) and challenged (polluted) trials. Detroit River fish were more aggressive than Belle River fish when challenged. Furthermore, Belle River fish showed increased locomotion when exposed to pollutants, whereas Detroit River fish were unaffected. The consistent difference in adult and juvenile behaviour across trials suggests a genetic response to pollution. Escape response on the other hand, showed inter-population differences, but no consistency between adults and juveniles, indicating that this behaviour is influenced by non-genetic factors. We discuss our data with respect to the potential adaptation of populations to pollution and the implications for prioritizing remediation efforts.
\end{abstract}

Keywords Acclimation - Aggression - Evolution · Genetic response $\cdot$ Locomotion $\cdot$ Pollution

R. D. Breckels · B. D. Neff $(\bowtie)$

Department of Biology, University of Western Ontario, London, ON N6A 5B7, Canada

e-mail: bneff@uwo.ca

\section{Introduction}

The potential effects of pollution on ecosystem health have received increased attention in recent years. Population expansion, industrialisation, and the intensification of agriculture and other industries have led to an increase in the amount and variety of pollutants introduced into the environment (Moss 1998; Hall et al. 2006). Aquatic environments are especially vulnerable because they are the recipient of most forms of anthropogenic waste through leaching, run-off, and dumping (Moyle and Leidy 1992). As a result, aquatic ecosystems, and especially their sediments, have become loaded with chemicals that greatly exceed natural concentrations. These sediments can act as both sinks and secondary sources of pollution (Cachot et al. 2007), which often result in bioaccumulation of pollutants that can lead to a variety of adverse effects in fishes and other aquatic animals. For example, 11 out of 19 studies of fish showed adverse changes in reproductive behaviours as a result of pollution (reviewed in Jones and Reynolds 1997). Changes were documented in display frequency, courtship duration, as well as performance of male-specific behaviours by masculinized females. These behavioural changes can decrease reproductive success and, ultimately, population health and viability (Grue et al. 2002).

Individuals and populations must adjust to the stress induced by chronic exposure to contaminants in order to persist in polluted environments. Thus, understanding behavioural differences induced by pollutants can provide insight into the mechanisms that allow individuals to persist in polluted environments. To this end, behavioural differences between contaminated and clean sites can be partitioned into physiological (individual level, including phenotypic plasticity) or genetic (population level) responses. A physiological response can be divided into 
two components: the acute response and the acclimation response. The acute response involves an alteration within an individual triggered by an acute or pulse stimulus and occurs over a short time period. These pollution induced alterations, such as affected fish that swim closer to the water's surface, can result in increased predation and consequently reduced fitness (reviewed in Scott and Sloman 2004). Generally, once the stimulus subsides, the individual returns to its normal behavioural and physiological state within 3 weeks (Kavitha and Rao 2007). Although acute responses help an organism to tolerate a stressor on a short-term basis, because they are often associated with reduced fitness, they do not provide a feasible response to chronic exposure to stressors.

In contrast, the acclimation response is a physiological modification within an individual that leads to tolerance of a stimulus (Grue et al. 2002). For example, guppies (Poecilia reticulata) acclimated to higher temperatures display higher thermal tolerances and survive longer in heated water than naïve fish (Chung 2001), and rainbow trout (Oncorhynchus mykiss) pre-exposed to aluminium display normal swimming behaviour and have higher survivorship than naïve fish when chronically exposed to the stressor (Allin and Wilson 2000). The acclimation response is typically a long-term or permanent change within individuals that results in increased fitness compared to the acute response. However, such physiological modifications are seldom heritable so offspring must also acclimate to the polluted environment. Acclimation during offspring development often channels resources away from other somatic processes such as growth, which can result in slowed development and reduced fitness (Ficke et al. 2007). Thus, the acclimation response can also carry fitness costs.

Genetic responses involve permanent genetic changes driven by natural selection. For example, Meyer and Di Giulio (2003) found a genetic response in survivorship in killifish (Fundulus heteroclitus) populations from polluted environments. Laboratory raised F1 and F2 offspring of descendants from the polluted Elizabeth River (Virginia, USA) were better adapted for survival and displayed normal development in contaminated water, even when they had no previous exposure, than fish from an unpolluted reference site. Fisher and Oleksiak (2007) also showed that killifish populations from polluted sites evolved adaptive changes in expression of metabolic genes compared to individuals from unpolluted, reference sites. There also are numerous examples of plants developing resistance to polluted soils (e.g. Eranen 2008). Thus, long-term exposure to environmental stressors can result in physiological responses, or alterations in the genetic makeup of a population brought about by selection for favourable traits.
Anthropogenic stressors, such as pollution, have occurred only recently on an evolutionary timescale. As such, a population that shows a beneficial genetic response to a stressor must have evolved the adaptation in a relatively short period, a process known as rapid evolution (e.g. Grant and Grant 1995; Hendry et al. 1998). Rapid evolution likely occurs through selection on standing (pre-existing) genetic variation, but can also involve selection for beneficial mutations (Barrett and Schulter 2007). Such beneficial mutations can come about from the mutagenic effects of the pollutants themselves. For example, Cachot et al. (2007) found that Japanese medaka (Oryzias latipes) exposed to polluted sediments had higher mutation rates than control fish. While most of the mutations are likely to be deleterious, increasing mutagenesis can also result in an increased frequency of favourable mutations. Polluted environments thereby provide an exceptional opportunity to study rapid evolution.

In this study, we examine the effects of long-term pollution exposure on the behaviour of brown bullheads, Ameiurus nebulosus (LeSueur 1819). Brown bullheads are an ideal species to study the effects of long-term pollution exposure in aquatic habitats. They are native to northeastern North America (Wheeler 1978) and are most abundant in the lakes and ponds of southern Ontario (Scott 1955). Brown bullheads sexually mature at about 3 years of age and produce large broods of up to 10,000 offspring (Blumer 1985). They are philopatric, benthic fish and have a high sediment affiliation, exposing them to pollutants that occur in the sediment. For example, brown bullheads from the heavily polluted Trenton Channel in the Detroit River have chemical burdens in their tissues similar to those of the sediment (Leadley et al. 1998; Yang and Baumann 2006).

We partition variation in aggression, locomotion, and escape response behaviour of fish from the polluted Detroit River and fish from a nearby clean site (Belle River) into physiological or genetic responses. We selected these behaviours because they are linked to individual performance (fitness) and can thereby affect population viability. For example, alterations in levels of aggression can affect an individual's acquisition of resources such as food, shelter, and mates (e.g. Fero et al. 2007). Locomotion is essential for many activities such as feeding, migration, reproduction, and predator avoidance (Baatrup and Bayley 1993) and is a good indicator of an individual's condition (Martin and Bateson 1993). Alterations in predator avoidance can result in an increased risk of predation (reviewed in Scott and Sloman 2004). Additionally, exposure to pollutants, including polycyclic aromatic hydrocarbons and heavy metals, has been shown to affect these behaviours; (1) aggression: reduced aggression in Nile tilapia, Oreochromis niloticus (Almeida et al. 2009) and three-spined 
stickleback, Gasterosteus aculeatus (Bell 2001); elevated aggression in mice (Jaeger et al. 1999), (2) locomotion: e.g. hyperactivity in sea catfish, Arius felis and sheepshead, Archosargus probatocephalus (Steele 1985), and woodlouse, Oniscus asellus (Bayley et al. 1997), and (3) predator avoidance: e.g. hyporeactivity in rainbow trout, Oncorhynchus mykiss (Ward et al. 2006); hyperactivity in fathead minnows, Pimephales promelas (Drummond and Russom 1990).

\section{Methods}

Brown bullheads were collected using electroshocking from two rivers in south-western Ontario, the highly industrialised Trenton Channel of the Detroit River $\left(42^{\circ} 10^{\prime} 54^{\prime \prime} \mathrm{N}\right.$, $\left.83^{\circ} 09^{\prime} 07^{\prime \prime} \mathrm{W}\right)$ and the less industrialised Belle River $\left(42^{\circ} 16^{\prime} 57^{\prime \prime} \mathrm{N}, 82^{\circ} 42^{\prime} 50^{\prime \prime} \mathrm{W}\right)$. The Detroit River is in the centre of a vast water system, receiving inputs from Lake St. Clair and the St. Clair River as well as from the cities of Detroit, Michigan and Windsor, Ontario. These inputs include effluents from both point and non-point sources including industrial, hazardous, and sewage treatment plant wastes (Drouillard et al. 2006). As a result, the Detroit River is an area of high contaminant loading, primarily by heavy metals, polycyclic aromatic hydrocarbons (PAHs), and polychlorinated biphenyls (PCBs), with the sediments on the western side of the river containing over 200 elevated organic chemical concentrations (Furlong et al. 1988; Arcand-Hoy and Metcalfe 1999). Indeed, 93\% of sample stations in Trenton Channel exceed threshold effect level sediment quality guidelines for PAHs and PCBs (Drouillard et al. 2006) and more than $16 \%$ of sample stations in the Detroit River exceed the severe effect level for heavy metals, with the maximum concentrations being confined to the Trenton Channel (Szalinska et al. 2006). Average hydrocarbon levels in the Detroit River are 1,195 parts per million (ppm) whereas these levels are only $77 \mathrm{ppm}$ in the Belle River (Nagy et al. 1984).

First, for the adult behavioural trial, during 17-19 June 2008, 24 adults from Trenton Channel and 25 from Belle River were collected, weighed, measured for total length, and individually marked with a PIT tag. The fish were then transported to Leadley Environmental Corporation (Essex County) $\left(42^{\circ} 06^{\prime} 11^{\prime \prime} \mathrm{N}, 82^{\circ} 55^{\prime} 44^{\prime \prime} \mathrm{W}\right)$ where they were held in $2.5 \mathrm{~m} \times 2.5 \mathrm{~m} \times 0.6 \mathrm{~m}$ holding tanks with 10 fish from the same site per tank. The fish were then exposed to a behavioural framework involving two different trials that allowed any variation between sites in aggression, locomotion, or escape response to be partitioned into physiological and genetic responses (Fig. 1). First, an "unchallenged" trial was conducted 3 weeks after capture in unstressed conditions (clean pond water) as direct acute
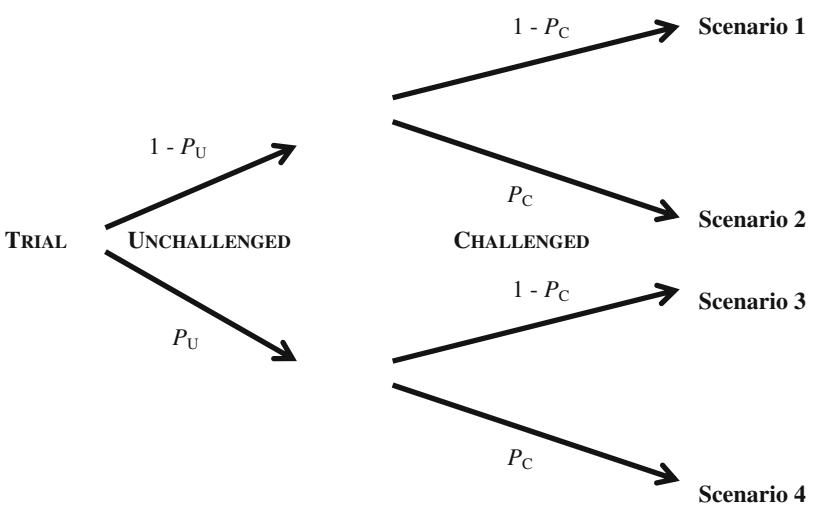

Fig. 1 A bifurcated tree detailing the four possible scenarios for the behavioural trials in brown bullheads (Ameiurus nebulosus). Arrows pointing upwards represent a difference in that behaviour between the two sites whereas arrows pointing downward represent no difference between the sites. $P_{\mathrm{U}}$ and $P_{\mathrm{C}}$ denote the probability that the null hypothesis is accepted at the unchallenged and challenged trial, respectively. Probability values associated with each arrow are presented in Table 1. The unchallenged trial was conducted after 3 weeks in clean water and the challenged trial was conducted after $24 \mathrm{~h}$ exposure to polluted sediments. As an example, scenario 1 represents a difference between the two sites at both the unchallenged and the challenged trial

responses to pollution stress from many chemicals are significantly reduced within 3 weeks (e.g. Djomo et al. 1996; Kavitha and Rao 2007). We thus assumed that any difference in behaviour between sites after the 3 week period reflected long-term responses (i.e. acclimation or genetic responses). Next, immediately afterwards, a "challenged" trial was conducted on the fish by placing them into holding tanks lined with a $10 \mathrm{~cm}$ layer of sediment collected from Trenton Channel (polluted environment) for $24 \mathrm{~h}$. The sediment was collected using Ponar sediment grabs. If fish from the two sites continued to differ in behaviour and also responded differently to the exposure to the polluted sediment, then it would be possible to attribute the long-term response to the pollution (see Fig. 1).

Second, for the juvenile behaviour trials, in May 2008, adults were collected and released into site-specific ponds at Leadley Environmental Corporation and allowed to spawn naturally. The ponds were monitored daily for freeswimming juveniles, which were collected and placed into separate site-specific ponds. To ensure a similar age in the experimental juvenile fish, we collected free-swimming individuals at first notice and over only a 2 day period in July 2008. In September 2008, 20 juveniles from each sitespecific pond (40 total) were collected and transported to the Freshwater Ecology Research Facility at the University of Western Ontario, where they were housed in 201 aquariums with 10 fish per aquarium. The juveniles were kept on a $12 \mathrm{~h}: 12 \mathrm{~h}$ light-dark cycle until experiments 
commenced in November 2008 (the juveniles were thus about 4 months old). The experiments followed the same framework as the adults. Consistent differences between the populations in the adults and the juveniles would ruleout an acclimation response and instead suggest a genetic response.

Each experimental fish was subjected to the behavioural experiments twice, once for the unchallenged trial and a second time for the challenged trial. The experiments commenced shortly after sunset and were performed under infrared light due to the nocturnal behaviour of the bullheads. Experiments were recorded using SONY DCRSR300 video cameras set to night vision mode and placed above the experimental aquaria. Prior to each set of trials, fish were moved from their holding tanks to circular experimental aquariums $(150 \mathrm{~cm}$ diameter and $20 \mathrm{~cm}$ depth for adults, $30 \mathrm{~cm}$ diameter and $8 \mathrm{~cm}$ depth for juveniles, which ensured similar fish-to-aquarium size ratios). First, locomotion was examined by observing the volitional distance (distance travelled in a given time) of fish from each site. Fish were placed in an experimental aquarium and, after a 15 min acclimatization period, were recorded for the next $15 \mathrm{~min}$. The distance travelled by each fish was measured by extracting a single frame image every $5 \mathrm{~s}$ from the video and determining the co-ordinates in a two-dimensional plane using Image $\mathbf{J}$ software. The distance travelled between each frame was determined using the Pythagorean Theorem and all the distances were summed to give an estimate of total distance travelled. Bullheads are benthic and consequently rarely leave contact with the sediment and swim into the water column. Thus, the two dimensional analysis provides an accurate measurement of the distance travelled.

Next, the escape response was examined. A stimulus was created by dropping a square weight into the water in the centre of the aquarium. Fish were recorded for $1 \mathrm{~min}$ preceding the stimulus and until their response had terminated (i.e. when the fish first ceased progressive forward motion, which typically occurred within $5 \mathrm{~s}$ ). The distance travelled and maximum burst speed during the response were recorded. The distance travelled was measured by extracting images from the video at 33 frames per second and measuring the total distance travelled (as above). For the burst speed, five single frame images were extracted per second from the video. The greatest distance between consecutive frames during the entire response was then multiplied by 5 to get an estimate of maximum burst speed (in $\mathrm{cm} / \mathrm{s}$ ).

Finally, after a 30 min rest period, the aggression displayed by fish from the different sites was observed by placing four fish, two from each site, selected to be of similar size, into an experimental aquarium. Fish were individually marked using small marks with liquid paper and were initially separated by a cross-shaped barrier measuring $150 \mathrm{~cm} \times 150 \mathrm{~cm}$. The barrier was removed after a 15 min acclimatization period and the aggressive behaviour of the fish was recorded for the next $10 \mathrm{~min}$. The number of aggressive acts, observed as chases and nudges, initiated by each individual were quantified. Aggression was calculated as the sum of aggressive acts performed by that individual divided by the total number of acts performed by all four individuals in that aquarium (to control for any tank effects and thereby standardize measures across tanks). After the unchallenged trials had finished, fish were moved to new holding tanks containing the polluted Trenton Channel sediment for $24 \mathrm{~h}$, after which the challenged trial commenced following the same procedures as outlined above. Time constraints restricted the aggression trials to 44 adults ( 22 from each site). The subset of fish was selected haphazardly from the original sample. Throughout the experiments, all fish were fed once daily with commercial fish food (Profishent, Martin Mills, ON).

$T$-tests were used to compare data between each site for all four behaviours and both trials, resulting in two $P$-values for each behaviour, which we refer to as $P_{\mathrm{U}}$ for the unchallenged trial, and $P_{\mathrm{C}}$ for the challenged trial. These values were converted into the probability that the null hypothesis - that there was no difference in behaviour between the sites-is false by subtracting them from one. The later values were multiplied through a bifurcated tree in order to estimate the probability of each of four scenarios: (1) different at both trials; (2) different at the unchallenged trial, but the same at the challenged trial; (3) the same at the unchallenged trial, but different at the challenged trial; (4) the same at both trials (Fig. 1). For example, if Trenton Channel fish were significantly more aggressive than Belle River fish across both trials, the most probable outcome would be scenario 1. Additionally, for each behaviour, we assessed our confidence in the probability of the most likely scenario by calculating a loglikelihood ratio (LOD score), which is the likelihood ratio of the most probable scenario compared to that of the next most probable scenario, using the equation:

$L O D=k \log \left(\frac{P_{1}+1}{P_{2}+1}\right)$

where $\mathrm{P}_{1}$ represents the most probable scenario, $\mathrm{P}_{2}$ represents the second most probable scenario, and $\mathrm{k}$ is a normalization constant equal to $1 / \log 2$ such that the LOD scores range between 0 and 1 . As an example, suppose scenario 1 was the most probable and scenario 2 the second most probable; a score of 1 gives complete support for scenario 1 as the most probable outcome, whereas a score of 0 indicates that the two scenarios are equally likely. 


\section{Results}

Adult brown bullheads were of similar sizes between the two sites (total body length: Belle River $(\mathrm{BR})=26.2 \pm 5.6 \mathrm{~cm}$; Trenton Channel $(\mathrm{TC})=24.9 \pm 8.2 \mathrm{~cm} ; t_{47}=1.35, P=$ 0.182 ). The juvenile brown bullheads did differ in size between the sites with the individuals from Belle River being longer than those from Trenton Channel $(\mathrm{BR}=5.7 \pm$ $\left.0.1 \mathrm{~cm} ; \quad \mathrm{TC}=5.1 \pm 0.1 \mathrm{~cm} ; \quad t_{38}=3.64, \quad P=0.001\right)$. Consequently, we included body length as a covariate for the analysis of juvenile behaviour, but body length had no effect on any of the recorded behaviours, and was removed from the final analysis. The results for the adult and juvenile behaviours are summarised in Tables 1 and 2 .

\section{Aggression}

For the adults, there was no difference between the two sites at the unchallenged trial $\left(t_{42}=0.05, P_{\mathrm{U}}=0.960\right)$; however, there was a difference between the sites at the challenged trial, with Trenton Channel fish being more aggressive than Belle River fish $\left(t_{42}=2.11, P_{\mathrm{C}}=0.041\right)$ (Fig. 2). Indeed, scenario 3 was the most probable outcome with strong statistical support $(92.1 \%$; LOD $=0.89)$. For the juveniles, the difference at the unchallenged trial was not significant $\left(t_{38}=0.72, P_{\mathrm{U}}=0.478\right)$. At the challenged trial, similar to the adults, Trenton Channel juveniles were more aggressive than Belle River juveniles, yet this difference was not significant $\left(t_{38}=-1.66, P_{\mathrm{C}}=0.105\right)$ (Fig. 2). The two most probable outcomes for the juveniles were scenarios 1 and 3 with roughly equal support (46.7 and $42.8 \%$ respectively; $L O D=0.04)$, suggesting that there was a difference at the challenged trial.

\section{Volitional distance}

The most probable outcome for the adults was scenario 1 (90.9\%; LOD $=0.81)$. Trenton Channel fish swam a greater distance at the unchallenged trial than Belle River fish $\left(t_{47}=-4.91, P_{\mathrm{U}}<0.001\right)$, yet Belle River fish dramatically increased their volitional distance during the challenged trial (paired $t$-test: $t_{20}=4.24, P<0.001$ ). Belle River fish swam farther than Trenton Channel fish during this latter period, consequently the difference between sites was not significant $\left(t_{42}=1.73, P_{\mathrm{C}}=0.091\right)$ (Fig. 3). The juveniles showed similar results to the adults with scenario 1 being the most probable $(52.4 \%$; LOD $=$ 0.09). Trenton Channel juveniles swam a greater distance in the unchallenged trial than Belle River juveniles $\left(t_{38}=2.09, P_{\mathrm{U}}=0.043\right)$, yet at the challenged trial, like the Belle River adults, Belle River juveniles significantly increased their volitional distance (paired $t$-test: $t_{19}=3.65$, $\mathrm{P}=0.002)$ to similar levels as Trenton Channel $\left(t_{34}=\right.$ $0.76, P_{\mathrm{C}}=0.452$ ) (Fig. 3).

Table 1 Mean $( \pm \mathrm{SE})$ behavioural measurements and $P$ values for both adult and juvenile brown bullheads (Ameiurus nebulosus)

\begin{tabular}{|c|c|c|c|c|c|}
\hline & Behaviour & Trial & Belle River & Trenton Channel & $P_{\mathrm{U} / \mathrm{C}}$ \\
\hline \multicolumn{6}{|l|}{ Adults } \\
\hline \multirow[t]{2}{*}{ Aggression } & \multirow[t]{2}{*}{ Relative aggression } & Unchallenged & $0.249 \pm 0.045$ & $0.251 \pm 0.037$ & 0.960 \\
\hline & & Challenged & $0.212 \pm 0.025$ & $0.288 \pm 0.026$ & 0.041 \\
\hline \multirow[t]{2}{*}{ Locomotion } & \multirow[t]{2}{*}{ Volitional distance $(\mathrm{cm})$} & Unchallenged & $532 \pm 94.6$ & $1161 \pm 85.9$ & $<0.001$ \\
\hline & & Challenged & $1688 \pm 296$ & $1063 \pm 215$ & 0.091 \\
\hline \multirow[t]{4}{*}{ Escape response } & \multirow[t]{2}{*}{ Distance travelled $(\mathrm{cm})$} & Unchallenged & $64.9 \pm 13.1$ & $41.4 \pm 8.47$ & 0.188 \\
\hline & & Challenged & $38.9 \pm 12.2$ & $50.3 \pm 12.8$ & 0.542 \\
\hline & \multirow[t]{2}{*}{ Burst speed $(\mathrm{cm} / \mathrm{s})$} & Unchallenged & $36.8 \pm 6.10$ & $27.2 \pm 4.99$ & 0.271 \\
\hline & & Challenged & $27.3 \pm 6.21$ & $27.5 \pm 7.49$ & 0.984 \\
\hline \multicolumn{6}{|l|}{ Juveniles } \\
\hline \multirow[t]{2}{*}{ Aggression } & \multirow[t]{2}{*}{ Relative aggression } & Unchallenged & $0.263 \pm 0.028$ & $0.237 \pm 0.023$ & 0.478 \\
\hline & & Challenged & $0.218 \pm 0.030$ & $0.282 \pm 0.024$ & 0.105 \\
\hline \multirow[t]{2}{*}{ Locomotion } & \multirow[t]{2}{*}{ Volitional distance $(\mathrm{cm})$} & Unchallenged & $1157 \pm 43.1$ & $1321 \pm 65.3$ & 0.043 \\
\hline & & Challenged & $1397 \pm 69.7$ & $1464 \pm 43.8$ & 0.452 \\
\hline \multirow[t]{4}{*}{ Escape response } & \multirow[t]{2}{*}{ Distance travelled $(\mathrm{cm})$} & Unchallenged & $19.1 \pm 8.31$ & $11.1 \pm 5.29$ & 0.422 \\
\hline & & Challenged & $15.9 \pm 4.60$ & $7.74 \pm 2.55$ & 0.156 \\
\hline & \multirow[t]{2}{*}{ Burst speed $(\mathrm{cm} / \mathrm{s})$} & Unchallenged & $14.1 \pm 3.86$ & $9.35 \pm 3.08$ & 0.344 \\
\hline & & Challenged & $20.9 \pm 4.99$ & $6.73 \pm 2.12$ & 0.022 \\
\hline
\end{tabular}

N.B.: $P$-values in bold represent significant results $(\alpha=0.05)$ 
Table 2 Summary of the probabilities of each of four scenarios from the bifurcated tree for adult and juvenile brown bullheads (Ameiurus nebulosus)

\begin{tabular}{|c|c|c|c|c|}
\hline Behaviour & Scenario 1 & Scenario 2 & Scenario 3 & Scenario 4 \\
\hline \multicolumn{5}{|l|}{ Adults } \\
\hline Aggression & 0.038 & 0.002 & $\mathbf{0 . 9 2 1}(0.886)$ & 0.039 \\
\hline Volitional distance & $\mathbf{0 . 9 0 9}(0.807)$ & 0.091 & $<0.001$ & $<0.001$ \\
\hline Burst speed & 0.012 & $\mathbf{0 . 7 1 7}(0.438)$ & 0.004 & 0.267 \\
\hline Distance travelled & 0.404 & $\mathbf{0 . 4 7 8}(0.074)$ & 0.054 & 0.064 \\
\hline \multicolumn{5}{|l|}{ Juveniles } \\
\hline Aggression & $\mathbf{0 . 4 6 7}(0.039)$ & 0.055 & 0.428 & 0.050 \\
\hline Volitional distance & $\mathbf{0 . 5 2 4}(0.089)$ & 0.433 & 0.024 & 0.019 \\
\hline Burst speed & $\mathbf{0 . 6 4 2}(0.297)$ & 0.014 & 0.336 & 0.008 \\
\hline Distance travelled & $\mathbf{0 . 4 8 7}(0.133)$ & 0.090 & 0.356 & 0.066 \\
\hline
\end{tabular}

Four behaviours were examined in both adult and common-garden reared juvenile fish. Probabilities in bold represent the most probable outcome. Values in parentheses represent the LOD score. As an example, suppose scenario 1 was the most probable and scenario 2 the second most probable; a score of 1 gives complete support for scenario 1 as the most probable outcome, whereas a score of 0 indicates that the two scenarios are equally likely. Scenario 1 represents a difference between the two sites at both trials; Scenario 2 represents a difference at the unchallenged trial, but not the challenged trial; Scenario 3 represents no difference at the unchallenged trial, but a difference at the challenged trial; and Scenario 4 represents no difference between the sites at either trial

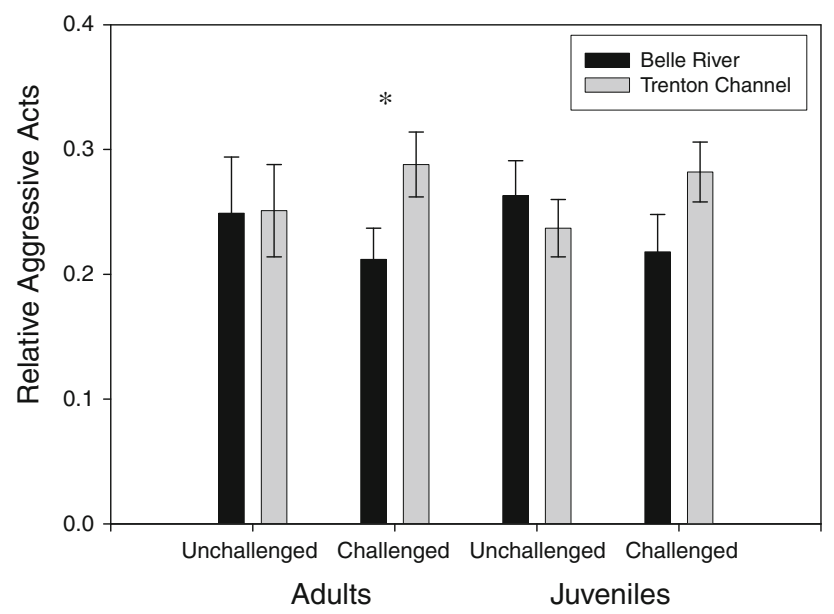

Fig. 2 Mean aggressive behaviour in brown bullheads (Ameiurus nebulosus). Relative aggressive acts was calculated by the total aggressive acts performed by an individual divided by the sum of the aggressive acts in the tank. Adults and common-garden reared juveniles were tested after 3 weeks in clean water (unchallenged) then $24 \mathrm{~h}$ exposure to polluted sediment (challenged). Error bars denote plus or minus one standard error of the mean. Asterisks represent significant differences between sites

\section{Escape response}

The most probable scenario for burst speed in adults was scenario $2(71.7 \%$; LOD $=0.44)$. There was no difference between sites at the unchallenged trial $\left(t_{38}=1.12, P_{\mathrm{U}}=\right.$ $0.271)$ or at the challenged trial $\left(t_{30}=0.02, P_{\mathrm{C}}=0.984\right)$. Unlike the adults, scenario 1 was the most probable outcome for burst speed for the juveniles (64.2\%; LOD $=0.30)$. Belle River and Trenton Channel juveniles

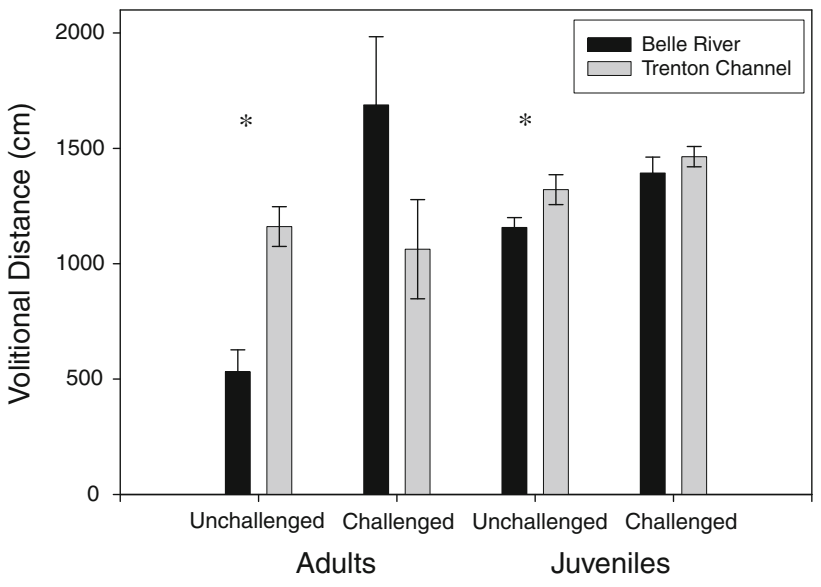

Fig. 3 Mean volitional distance in brown bullheads (Ameiurus nebulosus). Volitional distance was calculated as the distance an individual swam in $15 \mathrm{~min}$. Adults and common-garden reared juveniles were tested after 3 weeks in clean water (unchallenged) then $24 \mathrm{~h}$ exposure to polluted sediment (challenged). Error bars denote plus or minus one standard error of the mean. Asterisks represent significant differences between sites

showed similar burst speeds at the unchallenged trial ( $\left.t_{38}=-0.96, P_{\mathrm{U}}=0.344\right)$. At the challenged trial, Belle River juveniles increased their burst speed while Trenton Channel juveniles showed no difference, resulting in a significant difference between the two sites $\left(t_{34}=2.40\right.$, $\left.P_{\mathrm{C}}=0.022\right)$. The distance travelled in the adults showed scenario 2 as the most probable $(47.8 \%)$ albeit with low statistical support $(\mathrm{LOD}=0.07)$. There was no difference between the sites at the unchallenged trial $\left(t_{38}=1.34\right.$, $\left.P_{\mathrm{U}}=0.188\right)$ or at the challenged trial $\left(t_{30}=-0.62\right.$, 
$\left.P_{\mathrm{C}}=0.542\right)$. Scenario 1 was the most probable outcome for the juveniles $(48.8 \%$; $\mathrm{LOD}=0.13)$. There was no difference between the sites at the unchallenged trial $\left(t_{38}=0.21, P_{\mathrm{U}}=0.422\right)$ or the challenged trial $\left(t_{34}=\right.$ $\left.1.45, P_{\mathrm{C}}=0.156\right)$.

\section{Discussion}

Our study is one of the first attempts to document a genetic behavioural response to pollution. We found that bullheads from the highly polluted Detroit River appear to have evolved adaptations to pollution as measured by locomotion and aggressive behaviours. Specifically, Detroit River adults and common-garden reared juveniles were unaffected by the addition of polluted sediments, maintaining the same volitional distance when in clean or polluted water. Belle River fish, on the other hand, displayed an increase in activity with greater volitional distances when exposed to polluted water. Detroit River fish also maintained higher levels of aggression when exposed to pollution than Belle River fish. Increased aggression can be beneficial because individuals typically gain access to more resources, such as food, shelter, and mates (e.g. Fero et al. 2007). Conversely, an increase in locomotion behaviour in response to a stimulus is often a sign of stress in fish (Allin and Wilson 2000). The results from the other behaviours showed differences between the Detroit River and Belle River fish. However, those differences were not consistent between adults and juveniles, suggesting that non-genetic factors may be driving them.

While our results suggest an evolved response in locomotion and aggressive behaviours due to pollution, we cannot rule out other factors. First, parental effects could contribute to the differences we observed. Abnormalities in the offspring could stem from the fathers in the form of damage caused from chemicals in the Detroit River to the DNA carried by the sperm (e.g. Gray et al. 1999). Alternatively, chemicals from the river carried by the mothers could have been directly passed onto the offspring through the eggs. For many chemicals, the amount present in eggs correlates with the amount present in the mother (e.g. mercury: Hammerschmidt et al. 1999; and PAHs: Hall and Oris 1991). However, the burden in eggs is usually considerably lower than in the mothers (Serrano et al. 2008) and the burden in offspring is considerably lower than in the eggs (Beattie and Pascoe 1978). Given that our juveniles were reared in clean water from the egg stage for 4 months prior to testing, it is likely that any of the pollutants that might have been transferred would have been depurated (e.g. Djomo et al. 1996; Gardinali et al. 2004). Furthermore, it is difficult to understand why pollutants transferred maternally through the egg, or damage done to the germ-line DNA, would enable the Detroit River juveniles to subsequently dominate the Belle River juveniles in the challenge trials. On the other hand, it is possible that pollutants passed from the Detroit River mothers to their offspring is a trigger that 'turns-on' genes that allow the offspring to acclimate to the polluted environment. For example, offspring pre-exposed as eggs to cadmium survived longer than naïve offspring when both were later exposed to cadmium (Beattie and Pascoe 1978). Insomuch as those genes remain active or otherwise provide a physiological coping mechanism, the response we observed might not be an evolved response in the Detroit River fish. To test this alternative hypothesis, we could preexpose eggs from Belle River fish to the pollutants to see if a similar effect could be elicited from those fish, or we could conduct a multi-generation study with the Detroit River fish and look at second generation offspring whose parents had also been reared in an unpolluted environment (e.g. Meyer and Di Giulio 2003). Second, epigenetic effects have been shown to play a role in polluted environments through DNA methylation, microRNA, and histone modification (reviewed in Baccarelli and Bollati 2009). However, the importance of epigenetic effects in driving heritable behavioural responses to pollution or other stressors is unknown. Regardless, it is difficult for any study of heritability to definitely rule-out epigenetic effects as an alternative to heritable variation in DNA sequence.

It is also worth noting that although our fish were put in clean water for 3 weeks to remove any effects of the acute response, many chemicals remain stored in the body for a much longer period. We selected 3 weeks because this duration in clean conditions has been shown as sufficient time to depurate significant amounts of the organophosphate pesticide monocrotophos (Kavitha and Rao 2007), the heavy metals chromium (Parma et al. 2008), cadmium, and copper (Kraemer et al. 2005), the PAHs anthracene, phenanthrene, pyrene, and benzo[a]pyrene (Djomo et al. 1996), and the PCB Aroclor 1254 (Wang 1998). All of these chemicals are present in the Detroit River, although there is little known about the clearance times for many of the other chemicals in the river. Thus, it is possible that some residual chemicals continued to affect the Detroit River fish during the unchallenged trial. Nevertheless, residual burdens would not affect our interpretation of the challenged trial data and, for example, the increased performance of the Detroit River fish over the Belle River fish during the aggression trials. Thus, we feel that our data for aggression and locomotion are most consistent with a genetic response.

Traditionally it was thought that a genetic response was a slow process that would take hundreds of generations to occur (Darwin 1859), but more recent evidence suggests 
that such responses can occur over much shorter timescales (e.g. Grant and Grant 1995). Pollution in the Detroit River dates back to the late nineteenth century (US EPA 2007) or roughly 100 years ago. Brown bullheads tend to become sexually mature at 3 years of age, so 100 years represents at most 33 generations. Therefore, any evolved response to pollution in the Detroit River brown bullheads has occurred over a relatively short timescale. It is possible that large effective population sizes and large brood sizes contribute to the apparent rapid response. First, a large effective population size should contribute to large amounts of standing genetic variation on which selection can act. Second, a large brood size means that there are increased opportunities for favourable mutations to occur. Additionally, many contaminants can be genotoxic in that they have the ability to be mutagenic. Cachot et al. (2007) found that Japanese medaka (Oryzias latipes) exposed to sediment from the upper River Seine, Oissel, France showed significantly higher mutation rates than control fish. The sediments of the Seine in Oissel are known to have contaminant concentrations similar to the Detroit River. Indeed, Maccubbin et al. (1991) found the sediments of the Detroit River to be mutagenic. Increased mutagenesis, while resulting in increased deleterious mutations, could also result in an increased frequency of favourable mutations. Thus, the mutagenic nature of some of the chemicals in the Detroit River may have aided in the adaptation of the brown bullheads to contamination stress. Conceivably, the combination of short generation time, large brood sizes, large effective population sizes, and mutagenic chemicals, in conjunction with strong selective pressure have contributed to the apparent rapid evolved response in Detroit River bullhead behaviour.

It has been suggested that genetic changes in behavioural traits precede and direct subsequent morphological changes (West-Eberhard 2003). This idea stems from the fact that behavioural traits tend to be more labile than morphological traits (Wcislo 1989). That is, for each morphological state there can be many behavioural states, so the chance of producing a favourable trait is higher in behavioural traits than morphological traits (West-Eberhard 1989). Consequently, adaptive behavioural traits should become established first, followed by adaptive morphological traits. If an individual who resides in a polluted environment displays some heritable behaviour that is associated with a fitness benefit relative to other behaviours in the population, then the phenotype should be rapidly selected for and passed-on to the next generation. For example, in this study we found that Belle River fish significantly increased their locomotion when in polluted water, showing signs of stress, which in turn can lower fitness, whereas Trenton Channel fish were unaffected by the pollution. Additionally, brown bullheads from the
Detroit River were more aggressive than their Belle River counterparts when in polluted water. We did not look at morphological traits, so do not yet know if those traits have also responded to pollution, or the relative time scales with which behavioural and morphological traits have evolved in this population. Nevertheless, recently polluted environments do provide an opportunity to examine the relative rates of evolution of behavioural and morphological traits.

There is growing support for the presence of behavioural syndromes in populations. Behavioural syndromes are suites of correlated behaviours that occur in different contexts or situations (e.g. Hedrick 2000; reviewed by Sih et al. 2004). One of the more common behavioural syndromes is the aggressiveness/activity syndrome, where aggression is positively correlated with activity levels ( $\mathrm{Sih}$ et al. 2004). This relationship has been demonstrated in, for example, the field cricket, Gryllus integer in which activity, measured as an individual's latency to leave a glass vial into a novel environment, was positively correlated with aggressiveness, measured as the number of fights won by that individual (Kortet and Hedrick 2007). In our study, bullheads from the Detroit River were more aggressive and were more active than Belle River fish, which is in concordance with Kortet and Hedrick's results. Thus, at least for the aggressiveness/activity syndrome, our data suggest a behavioural syndrome exists in bullhead as well.

Remediation plans aim to restore the ecosystem to some level of acceptable integrity or health. Consequently, many remediation plans target areas with a long history of pollution, such as the Detroit River and Lake Erie (e.g. Heidtke et al. 2002). Between 1993 and 2001, an estimated $\$ 130$ million was spent on sediment remediation activities in the Detroit River and western Lake Erie as part of the Detroit River Remedial Action Plan (Heidtke et al. 2002). However, it is apparent that these areas are still loaded with chemicals at levels well above the policy guidelines (Drouillard et al. 2006). The Detroit River has a long history of contamination and our data now show that at least one native species may have evolved in response to the pollution although a more thorough community-level analysis is needed. We suggest that it may be time to start prioritising our remediation action plans with some consideration of potential adaptation to a stressor by local flora and fauna. Newly-polluted ecosystems or ones that are experiencing rapid population declines ought to be top of our priority list. Conversely, areas with a long history of pollution might be prioritized lower if resident species show signs of adaptation to the current pollution levels. Additionally, if areas such as the Detroit River are fully restored to a non-polluted state, some consideration should be given to ensure that the resident species are fully viable in the 'new' clean environment. For example, it is conceivable that the brown bullhead presently in the Detroit 
River would be less adapted to the clean environment and would be prone to invasion by other non-local species that occupy a similar niche. As humans continue to pollute aquatic ecosystems, the need for prioritizing remediation efforts will become increasingly important to effectively use conservation resources. Our study suggests that consideration of adaptive and physiological responses to stressors should also be considered when prioritizing sites.

Acknowledgements We thank T. Leadley, L. Soderberg, M. Farwell, C. Beneteau, L. Crawford, and T. Pitcher for their help in the field. We also thank S. Colborne, L. Crawford, M. Evans, S. Garner, T. Hain, D. Heath, J. Van Zwol, and two anonymous reviewers for their comments on the manuscript. This work was funded by an NSERC Strategic Project Grant and the University of Western Ontario.

\section{References}

Allin CJ, Wilson RW (2000) Effects of pre-acclimation to aluminium on the physiological and swimming behaviour of juvenile rainbow trout (Oncorhynchus mykiss) during a pulsed exposure. Aquat Toxicol 51:213-224

Almeida JA, Barreto RE, Novelli ELB, Castro FJ, Moron SE (2009) Oxidative stress biomarkers in fish exposed to aquatic cadmium contamination. Neotrop Ichthyol 7:103-108

Arcand-Hoy LD, Metcalfe CD (1999) Biomarkers of exposure of brown bullheads (Ameiurus nebulosus) to contaminants in the lower Great Lakes, North America. Environ Toxicol Chem 18:740-749

Baatrup E, Bayley M (1993) Quantative analysis of spider locomotion employing computer-automated video tracking. Physiol Behav 54:83-90

Baccarelli A, Bollati V (2009) Epigenetics and environmental chemicals. Curr Opin Pediatr 21:243-251

Barrett RDH, Schulter D (2007) Adaptation from standing genetic variation. Trends Ecol Evol 23:38-44

Bayley M, Baatrup E, Bjerregaard P (1997) Woodlouse locomotor behaviour in the assessment of clean and contaminated field sites. Environ Toxicol Chem 16:2309-2314

Beattie JH, Pascoe D (1978) Cadmium uptake by rainbow trout, Salmo gairdneri eggs and alevins. J Fish Biol 13:631-637

Bell AM (2001) Effects of an endocrine disrupter on courtship and aggressive behaviour of male three-spined stickleback, Gastrerosteus aculeatus. Anim Behav 62:775-780

Blumer LS (1985) Reproductive natural history of brown bullhead Ictalurus nebulosus in Michigan. Am Midl Nat 114:318-330

Cachot J, Law M, Pottier D, Peluhet L, Norris M, Budzinski H, Winn R (2007) Characterization of toxic effects of sediment-associated organic pollutants using the $\lambda$ transgenic medaka. Environ Sci Technol 41:7830-7836

Chung KS (2001) Critical thermal maxima and acclimation rate of the tropical guppy Poecilla reticulata. Hydrobiologia 462:253-257

Darwin C (1859) The origin of species by means of natural selection. John Murray, London

Djomo JE, Garrigues P, Narbonne JF (1996) Uptake and depuration of polycyclic aromatic hydrocarbons from sediment by the zebrafish (Brachydanio rerio). Environ Toxicol Chem $15: 1177-1181$

Drouillard KG, Tomczak M, Reitsma S, Haffner GD (2006) A riverwide survey of polychlorinated biphenyls (PCBs), polycyclic aromatic hydrocarbons (PAHs), and selected organochlorine pesticide residues in sediments of the Detroit River-1999. J Great Lakes Res 32:209-226

Drummond RA, Russom CL (1990) Behavioural toxicity syndromes: a promising tool for assessing toxicity mechanisms in juvenile fathead minnows. Environ Toxicol Chem 9:37-46

Eranen JK (2008) Rapid evolution towards heavy metal resistance by mountain birch around two subarctic copper-nickel smelters. J Evol Biol 21:492-501

Fero K, Simon JL, Jourdie V, Moore PA (2007) Consequences of social dominance on crayfish resource use. Behaviour 144:61-82

Ficke AD, Myrick CA, Hansen LJ (2007) Potential impacts of global climate change on freshwater fisheries. Rev Fish Biol Fish 17:581-613

Fisher MA, Oleksiak MF (2007) Convergence and divergence in gene expression among natural populations exposed to pollution. BMC Genomics 8:108

Furlong ET, Carter DS, Hites RA (1988) Organic contaminants in the sediment from the Trenton Channel of the Detroit River, Michigan. J Great Lakes Res 14:489-501

Gardinali PR, Sericano JL, Wade TL (2004) Uptake and depuration of toxic halogenated aromatic hydrocarbons by the American oyster (Crassostrea virginica): a field study. Chemosphere 54:61-70

Grant PR, Grant BR (1995) Predicting microevolutionary responses to directional selection on heritable variation. Evolution 49:241-251

Gray MA, Teather KL, Metcalfe CD (1999) Reproductive success and behaviour of Japanese medaka (Oryzias latipes) exposed to 4-tert-octylphenol. Environ Toxicol Chem 18:2587-2594

Grue CE, Gardner SC, Gibert PL (2002) On the significance of pollutant-induced alterations in the behaviour of fish and wildlife. In: Dell'Omo G (ed) Behavioural ecotoxicology. Wiley, Chichester, pp 1-90

Hall AT, Oris JT (1991) Anthracene reduces reproductive potential and is maternally transferred during long-term exposure in fathead minnows. Aquat Toxicol 19:249-264

Hall JD, O'Connor K, Ranieri J (2006) Progress toward delisting a Great Lakes Area of Concern: the role of integrated research and monitoring in the Hamilton Harbour remedial action plan. Environ Monit Assess 113:227-243

Hammerschmidt CR, Wiener JG, Frazier BE, Rada RG (1999) Methylmercury content of eggs in yellow perch related to maternal exposure in four Wisconsin lakes. Environ Sci Technol 33:999-1003

Hedrick AV (2000) Crickets with extravagant mating songs compensate for predation risk with extra caution. Proc R Soc Lond B Biol Sci 267:671-675

Heidtke TM, Hartig J, Yu B (2002) Evaluating ecosystem results of $P C B$ control measures within the Detroit River-western Lake Erie basin. Great Lakes National Program Office, U.S. Environmental Protection Agency, EPA-905-R-03-001, Chicago, IL

Hendry AP, Hensleigh JE, Reisenbichler RR (1998) Incubation temperature, developmental biology, and the divergence of sockeye salmon (Oncorhynchus nerka) within Lake Washington. Can J Fish Aquat Sci 55:1387-1394

Jaeger JW, Carlson IH, Porter WP (1999) Endocrine, immune, and behavioural effects of aldicarb (carbamate), atrazine (triazine) and nitrate (fertilizer) mixtures at groundwater concentrations. Toxicol Ind Health 15:133-151

Jones KC, Reynolds JD (1997) Effects of pollution on reproductive behaviour of fishes. Rev Fish Biol Fish 7:463-491

Kavitha P, Rao VJ (2007) Oxidative stress and locomotion behaviour response as biomarkers for assessing recovery status of mosquito fish, Gambusia affinis, after lethal effect of an organophosphate pesticide, monocrotophos. Pestic Biochem Physiol 87:182-188

Kortet R, Hedrick A (2007) Abehavioural syndrome in the field cricket Gryllus integer: intrasexual aggression is correlated with activity in a novel environment. Biol J Linn Soc 91:475-482 
Kraemer LD, Campbell PGC, Hare L (2005) A field study examiming metal elimination in juvenile yellow perch (Perca flavescens). Aquat Toxicol 75:108-126

Leadley TA, Balch G, Metcalfe CD, Lazar R, Mazak E, Habowsky J, Haffner GD (1998) Chemical accumulation and toxicological stress in three brown bullhead (Ameiurus nebulosus) populations of the Detroit River, Michigan, USA. Environ Toxicol Chem 17:1756-1766

Maccubbin AE, Ersing N, Frank ME (1991) Mutagenicity of sediments from the Detroit River. J Great Lakes Res 17:314-321

Martin P, Bateson P (1993) Measuring behaviour: an introductory guide, 2nd edn. Cambridge University Press, Cambridge, UK

Meyer JN, Di Giulio RT (2003) Heritable adaptation and fitness costs in killifish (Fundulus heteroclitus) inhabiting a polluted estuary. Ecol Appl 13:490-503

Moss B (1998) Ecology of fresh waters: man and medium, past to future. Blackwell Science Ltd, Blackwell Publishing, Oxford, UK

Moyle PB, Leidy RA (1992) Loss of biodiversity in aquatic ecosystems: evidence from fish faunas. In: Fielder PL, Jain SK (eds) Conservation biology. Chapman and Hall, New York, pp 127-169

Nagy E, Murdoch P, Murdoch A, Thomas RL (1984) Hydrocarbons in the surficial sediments of Lakes St Clair, Erie, and Ontario. Environ Geol 6:31-37

Parma MJ, Campana M, Loteste A (2008) Uptake and elimination of chromium in Cnesterodon decemmaculatus; Pisces; Poeciliidae, after sub-chronic experimental exposure. Fresenius Environ Bull 17:293-297

Scott WB (1955) Freshwater fishes of Eastern Canada, 2nd edn. University of Toronto Press, Canada, p 72

Scott GR, Sloman KA (2004) The effects of environmental pollutants on complex fish behaviour: integrating behavioural and physiological indicators of toxicity. Aquat Toxicol 68:369-392
Serrano R, Blanes MA, Lopez FJ (2008) Maternal transfer of organochlorine compounds to oocytes in wild and farmed gilthead sea bream (Sparus aurata). Chemosphere 70:561-566

Sih A, Bell A, Johnson JC (2004) Behavioural syndromes: an ecological and evolutionary overview. Trends Ecol Evol 19: 372-378

Steele CW (1985) Latent behavioural toxicity of copper to sea catfish, Arius felis, and sheepshead, Archosargus probatocephalus. J Fish Biol 27:643-654

Szalinska E, Drouillard KG, Fryer B, Haffner GD (2006) Distribution of heavy metals in sediments of the Detroit River. J Great Lakes Res 32:442-454

U.S. Environmental Protection Agency (2007) Detroit River-Western Lake Erie Basin Indicator Project: oil pollution of the Detroit and Rouge Rivers. http://www.epa.gov/med/grosseile_site/indicators/ oilspills.html

Wang JS (1998) Accumulation and depuration of aqueous and dietary PCB (Aroclor 1254) by striped bass (Morone saxatilis). Bull Environ Contam Toxicol 60:104-111

Ward AJW, Duff AJ, Currie S (2006) The effects of the endocrine disrupter 4-nonylphenol on the behaviour of juvenile rainbow trout (Oncorhynchus mykiss). Can J Fish Aquat Sci 63:377-382

Wcislo WT (1989) Behavioural environments and evolutionary change. Annu Rev Ecol Syst 20:137-169

West-Eberhard MJ (1989) Phenotypic plasticity and the origins of diversity. Annu Rev Ecol Syst 20:249-278

West-Eberhard MJ (2003) Developmental plasticity and evolution. Oxford University Press, Oxford, UK, p 24

Wheeler A (1978) Ictalurus melas (Rafinesque, 1820) and I. nebulosus (LeSueur, 1819): the North American catfishes in Europe. J Fish Biol 12:435-439

Yang X, Baumann PC (2006) Biliary PAH metabolites and the hepatosomatic index of brown bullheads from Lake Erie tributaries. Ecol Indic 6:567-574 